\title{
Demineralized enamel reduces margin integrity of self-etch, but not of etch-and-rinse bonded composite restorations
}

Körner, Philipp ; Sulejmani, Aljmedina ; Wiedemeier, Daniel B ; Attin, Thomas ; Tauböck, Tobias T

\begin{abstract}
The aim of this study was to investigate margin integrity of Class $\mathrm{V}$ composite restorations in demineralized and sound enamel after bonding with different etch-and-rinse and self-etch adhesive systems. Out of a total of 60 specimens from bovine incisors, 30 specimens were demineralized (21 days, acid buffer, $\mathrm{pH} 4.95$ ) to create artificial enamel lesions. Circular Class V cavities were prepared in all 60 specimens and treated with either an unfilled etch-and-rinse adhesive (Syntac Classic; Ivoclar Vivadent), a filled etch-and-rinse adhesive (Optibond FL; Kerr), or a self-etch adhesive (iBond Self Etch; Heraeus) ( $\mathrm{n}=10$ per group). The cavities were restored with a nanofilled resin composite and thermocycled $\left(5000 \times, 5-55^{\circ} \mathrm{C}\right)$. Scanning electron microscopy was used to evaluate margin integrity of the composite restorations, and the percentage of continuous margin was statistically analyzed $(\alpha=0.05)$. Demineralized enamel led to a significantly lower margin integrity when the self-etch adhesive iBond Self Etch was applied, but did not affect margin integrity when the etch-and-rinse adhesives Optibond FL (filled) or Syntac Classic (unfilled) were used. No significant differences in margin integrity in sound and demineralized enamel were observed between the different adhesives. Demineralized enamel reduces margin integrity of composite restorations when bonded with a self-etch adhesive, but does not affect margin integrity when an etch-and-rinse approach is used.
\end{abstract}

DOI: https://doi.org/10.1007/s10266-018-0398-6

Posted at the Zurich Open Repository and Archive, University of Zurich

ZORA URL: https://doi.org/10.5167/uzh-167376

Journal Article

Accepted Version

Originally published at:

Körner, Philipp; Sulejmani, Aljmedina; Wiedemeier, Daniel B; Attin, Thomas; Tauböck, Tobias T (2019). Demineralized enamel reduces margin integrity of self-etch, but not of etch-and-rinse bonded composite restorations. Odontology / the Society of the Nippon Dental University, 107(3):308-315.

DOI: https://doi.org/10.1007/s10266-018-0398-6 


\section{Demineralized enamel reduces margin integrity of self-etch, but not of etch-and-rinse bonded composite restorations}

Philipp Körner ${ }^{1, *}$, Aljmedina Sulejmani ${ }^{1}$, Daniel B. Wiedemeier ${ }^{2}$, Thomas Attin ${ }^{1}$, Tobias T. Tauböck ${ }^{1}$

${ }^{1}$ Clinic of Preventive Dentistry, Periodontology and Cariology, Center for Dental Medicine, University of Zurich, Plattenstrasse 11, CH-8032 Zurich, Switzerland

${ }^{2}$ Statistical Services, Center of Dental Medicine, University of Zurich, Plattenstrasse 11, CH-8032 Zurich, Switzerland

Keywords: margin integrity, demineralized enamel, etch-and-rinse, self-etch adhesive, resin composite

* Corresponding author at:

Clinic of Preventive Dentistry, Periodontology and Cariology

Center of Dental Medicine, University of Zurich

Plattenstrasse 11, CH-8032 Zurich, Switzerland

Tel: +41 4463433 86, Fax: +4144634 4308

E-mail: philipp.koerner@zzm.uzh.ch 


\begin{abstract}
The aim of this study was to investigate margin integrity of Class V composite restorations in demineralized and sound enamel after bonding with different etch-and-rinse and self-etch adhesive systems. Out of a total of 60 specimens from bovine incisors, 30 specimens were demineralized (21 days, acid buffer, $\mathrm{pH} 4.95$ ) to create artificial enamel lesions. Circular Class V cavities were prepared in all 60 specimens and treated with either an unfilled etch-and-rinse adhesive (Syntac Classic; Ivoclar Vivadent), a filled etch-and-rinse adhesive (Optibond FL; Kerr), or a self-etch adhesive (iBond Self Etch; Heraeus) ( $\mathrm{n}=10$ per group). The cavities were restored with a nanofilled resin composite and thermocycled $(5000 \mathrm{x}$, 5-55 ${ }^{\circ} \mathrm{C}$ ). Scanning electron microscopy was used to evaluate margin integrity of the composite restorations, and the percentage of continuous margin was statistically analyzed $(\alpha=0.05)$. Demineralized enamel led to significantly lower margin integrity when the selfetch adhesive iBond Self Etch was applied, but did not affect margin integrity when the etch-and-rinse adhesives Optibond FL (filled) or Syntac Classic (unfilled) were used. No significant differences in margin integrity in sound and demineralized enamel were observed between the different adhesives. Demineralized enamel reduces margin integrity of composite restorations when bonded with a self-etch adhesive, but does not affect margin integrity when an etch-and-rinse approach is used.
\end{abstract}




\section{Introduction}

Resin-based composites are increasingly popular for direct dental restorations $[1,2]$. These materials allow for lesion-oriented, minimally invasive caries treatment, since they can be adhesively bonded to the remaining tooth structure without the need for macro-mechanical retention [3].

However, dentists are often confronted with demineralized enamel margins during the process of caries excavation. Despite minimally invasive treatment approaches, caries excavation in daily routine commonly does not only include softened and infected dentin, but also demineralized enamel, and is often extended to sound enamel margins [4,5]. Especially in extensive areas of demineralized enamel margins, this concept may lead to a high and potentially disproportional loss of dental hard tissue [6]. Therefore, the question arises, whether minimally invasive caries excavation needs to be extended to sound enamel margins in order to obtain optimum margin integrity of the restorations, and thus to guarantee an optimum sealing ability.

Adhesive bonding materials differ in filler content, polymerization shrinkage and viscosity, which might influence their penetration in sound and demineralized enamel $[7,8]$. Due to its good performance in multiple laboratory studies and clinical research, the filled adhesive Optibond FL can be regarded as an established and well investigated etch-and-rinse adhesive [9-11]. The unfilled adhesive Syntac Classic and self-etch adhesive iBond Self Etch have also been used in various in vitro and in vivo studies and are considered to be sound representatives of their respective group [12-14]. Thus, the applicability of these adhesive systems and their influence on margin integrity of composite restorations in demineralized and sound enamel seem to be of great interest.

Therefore, the aim of the present study was to evaluate margin integrity of composite restorations in demineralized and sound enamel after application of these different etch-and-rinse and self-etch adhesive systems. The null hypotheses were that 1) margins in 
sound or demineralized enamel and 2) different kinds of adhesive systems do not affect margin integrity of composite restorations.

\section{Materials and methods}

\section{Specimen preparation and demineralization}

Fig. 1 illustrates the experimental design. A total of 60 specimens were prepared from the crowns of freshly extracted, undamaged, permanent bovine incisors stored in tap water until use, and randomly assigned into six groups of ten specimens each. The cementum layer was entirely removed by using polishing discs (Sof-Lex Pop-on; 3M ESPE, St. Paul, MN, USA). Enamel in groups 1-3 was demineralized by storing the specimens for 21 days at $37{ }^{\circ} \mathrm{C}$ in an

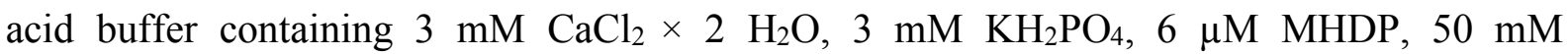
$\mathrm{CH}_{3} \mathrm{COOH}, \mathrm{KOH}$ (to adjust the $\mathrm{pH}$ to 4,95), and distilled water [15]. In order to keep the $\mathrm{pH}$ constant, the solution was renewed every day. The pulp cavum of the specimens was blocked and sealed with nail polish before demineralization to avoid internal demineralization. A cross-section of an artificially demineralized enamel lesion, recorded using a transmitted light microscope with a 10x objective (BX60; Olympus, Volketswil, Switzerland) and a CMOS color camera (DP74; Olympus), is shown in Fig. 2. The mineral density of demineralized and sound enamel was exemplarily measured by transverse microradiography (TMR) [16] on one additional specimen, and is given in Fig. 3. After demineralization of

groups 1-3, standardized Class V cavities (diameter: $3 \mathrm{~mm}$, depth: $2 \mathrm{~mm}$, bevel edge: $1 \mathrm{~mm}$ ) were prepared in the labial surfaces of all 60 specimens using spherical headed diamond burs (D126; Garant, Munich, Germany). The entire margin of the cavity was localized in enamel. 


\section{Bonding procedure}

Cavities of the 60 prepared specimens were treated with either an unfilled etch-and-rinse adhesive (Syntac Classic; Ivoclar Vivadent, Schaan, Liechtenstein), a filled etch-and-rinse adhesive (Optibond FL; Kerr, Orange, CA, USA), or a self-etch adhesive (iBond Self Etch; Heraeus, Hanau, Germany). Detailed information and composition of the adhesives are given in Table 1. The bonding procedure in the different groups strictly based on the manufacturers' instructions for use, and was performed as follows:

\section{Unfilled etch-and-rinse adhesive (Syntac Classic) - Groups 1 and 4:}

Enamel and dentin surfaces of demineralized $(n=10$, group 1$)$ and not demineralized $(n=10$, group 4) specimens were etched with 37\% phosphoric acid gel (Total Etch; Ivoclar Vivadent) for $15 \mathrm{~s}$ before rinsing with water for $30 \mathrm{~s}$. After gently air drying, the adhesive system (Syntac Classic; Ivoclar Vivadent) consisting of Syntac Primer (15 s), Syntac Adhesive (10 s) and Heliobond (15 s) was applied and light cured (20 s).

For photoactivation, a polywave LED curing unit (Bluephase G2; Ivoclar Vivadent) was used in all groups (1-6) at an output irradiance of at least $1,100 \mathrm{~mW} / \mathrm{cm}^{2}$. Output irradiance of the curing unit was checked periodically during the experiment with a calibrated power meter (FieldMaxII-TO; Coherent, Santa Clara, CA, USA).

\section{Filled etch-and-rinse adhesive (Optibond FL) - Groups 2 and 5:}

Prior to application of the filled etch-and-rinse adhesive (Optibond FL; Kerr), enamel and dentin surfaces of demineralized $(n=10$, group 2$)$ and not demineralized $(n=10$, group 5$)$ specimens were etched with $37 \%$ phosphoric acid gel for $15 \mathrm{~s}$, and rinsed for $30 \mathrm{~s}$. After primer application for $15 \mathrm{~s}$ and gently air drying for $5 \mathrm{~s}$, the adhesive was applied for $15 \mathrm{~s}$, gently air-thinned, and light cured for $20 \mathrm{~s}$. 


\section{Self-etch adhesive (iBond Self Etch) - Groups 3 and 6:}

Enamel and dentin surfaces of demineralized $(n=10$, group 3$)$ and not demineralized $(n=10$, group 6) specimens were conditioned by applying the self-etch adhesive (iBond Self Etch; Heraeus) for $20 \mathrm{~s}$, followed by gently air drying (5 s) and light curing (20 s).

\section{Composite application and thermocycling}

After application of the different adhesive systems, all 60 pretreated Class V cavities were restored in one increment with a nanofilled composite material (Filtek Supreme XTE; 3M ESPE; shade A2B, LOT N535229), and light cured for 20 s. Surgical scalpel blades (No. 12D; Gebr. Martin, Tuttlingen, Germany) were used to remove excess before the restorations were finished and polished with silicon instruments (Brownie Mini-Points and Greenie MiniPoints; Shofu Dental Corporation, San Marcos, CA, USA) and polishing brushes (Occlubrush; Kerr). A microscope was used at 25x magnification (Stemi 2000; Zeiss, Oberkochen, Germany) during placement of the restorations and in order to check them. Subsequently, the specimens were artificially aged by thermocycling - 5000 times in water between $5{ }^{\circ} \mathrm{C}$ and $55^{\circ} \mathrm{C}$, dwell time of $20 \mathrm{~s}$ in each temperature bath, transfer time of $10 \mathrm{~s}$ (Willytec; Gräfelfing, Germany) [17].

\section{Assessment of margin integrity}

Negative copies of each restoration were taken with an A-polyvinylsiloxane material (President Light Body; Coltène, Altstätten, Switzerland) after thermocycling. The impressions were poured with epoxy resin (Epoxyharz L; R\&G Faserverbundwerkstoffe, Waldenbuch, Germany) to receive positive replicas, and subsequently glued to aluminum carriers (Cementit Universal; Merz\&Benteli, Niederwangen, Switzerland). The replicas were sputter-coated with gold (Sputter SCD 030; Balzers Union, Balzers, Liechtenstein) [18] and subjected to a quantitative margin analysis using scanning electron microscopy at $20 \mathrm{kV}$ and $200 \mathrm{x}$ 
magnification (Vega TS5136XM; Tescan, Brno, Czech Republic). Margin qualities were classified as "continuous", "non-continuous" or "not judgeable" by one trained and blinded examiner, as performed in previous studies [19,20]. Margin integrity between enamel and restoration was expressed in percentage of "continuous margin" in relation to the entire judgeable margin $[8,21]$.

\section{Statistical analysis}

As part of descriptive statistics, means and standard deviation were computed. Normality assumptions were checked using Kolmogorov-Smirnov and Shapiro-Wilk tests. Two-way ANOVA with the two factors "demineralization" (two levels) and "adhesive system" (three levels) including interaction was then fitted to the margin integrity data. Subsequently, differences in the percentage of continuous margins between sound and demineralized enamel within each adhesive system were analyzed using post-hoc t-tests. The level of significance was set at 5\%. All statistical analyses and plots were done with the statistical software R version 3.2.2 (The R Foundation for Statistical Computing, Vienna, Austria; www.Rproject.org).

\section{Results}

The percentage of continuous margins (margin integrity) in demineralized and sound enamel after application of the different adhesive systems is presented in Fig. 4. While two-way ANOVA revealed no significance for the factor "adhesive system", the factor "demineralization" showed significant influence on margin integrity $(p=0.010)$. No significant interaction between the two factors was observed.

Demineralized enamel led to significantly lower margin integrity when the self-etch adhesive iBond ( $p=0.039)$ was applied, but did not affect margin integrity when the etchand-rinse adhesives Optibond FL (filled) or Syntac Classic (unfilled) were used. No 
significant differences in margin integrity in sound and demineralized enamel were observed between the different adhesives. Representative SEM micrographs of continuous and noncontinuous margins are shown in Figs. 5 and 6.

\section{Discussion}

The results of this study indicate that demineralized enamel leads to significantly lower margin integrity of composite restorations compared to sound enamel, in case that the selfetch adhesive iBond Self Etch is used, but does not significantly affect margin integrity when the etch-and-rinse adhesives Optibond FL or Syntac Classic are applied. Thus, the first null hypothesis was partly rejected.

Bovine teeth are often used in studies evaluating margin integrity [20,22]. Due to a high degree of homogeneity and a similar chemical structure to human enamel [23], they are considered to be an appropriate alternative to human enamel [24]. Artificial enamel lesions were shown to have a histological structure similar to white-spot lesions and enamel caries, and were produced in accordance with previous in vitro studies investigating demineralized enamel $[8,16,25-27]$. The lesion depths (Fig. 2) were comparable to those described in these studies. However, natural enamel lesions can be deeper than artificial lesions, which might affect resin penetration under natural conditions [28].

In the present study, composite restorations bonded with the self-etch adhesive showed similarly high margin integrity in sound enamel as the etch-and-rinse adhesives. This finding is in agreement with other studies investigating margin integrity of self-etch adhesives in sound enamel $[29,30]$. Nevertheless, there are also studies describing significantly lower margin integrity in case that self-etch adhesives are used [12,31].

Beside correct application, margin integrity of composite fillings is influenced by the type of etching, filler content, resin viscosity and penetration ability of adhesive materials $[32,33]$. As the different adhesives in this study showed similarly high margin integrity in 
sound enamel, the question arises, to what extend demineralized enamel margins are responsible for the significantly lower margin integrity in case the self-etch adhesive was applied in demineralized enamel. An important step in order to enable deep resin penetration is to establish an adequate etching pattern [34]. Therefore, surface layers must be removed sufficiently [35]. Specimens were etched and treated in accordance with manufacturers' instructions meaning that they were etched with $37 \%$ phosphoric acid before application of the etch-and-rinse adhesives or acidic self-etch monomers. Acidic monomers in self-etch adhesives are less potent in terms of etching efficacy compared to conventional acids, conceivably leading to an irregular etching pattern [26,36], and reduced resin penetration into the lesion bulk [37]. The present study suggests that the etching efficacy of the self-etch adhesive might be even lower in demineralized enamel which might have resulted in an insufficient removal of the demineralized surface layer combined with an irregular etchingpattern, and thus limited penetration.

Enamel margin integrity of self-etch adhesives has been shown to benefit from preetching with phosphoric acid [38,39]. Therefore, it would be of interest to investigate the influence of pre-etching demineralized enamel with phosphoric acid on margin integrity in further studies. A recent study showed that a positive effect on margin integrity of composite restorations placed in demineralized enamel can be achieved through infiltration of demineralized enamel with a caries infiltrant before application of a self-etch adhesive [8].

The good performance of Optibond FL and Syntac Classic (etch-and-rinse adhesives) in this study is in agreement with literature findings, where these adhesives consistently showed predictable bonding ability in both laboratory and clinical trials [14,40-43]. However, the present study also revealed that the factor adhesive system, other than the factor demineralization, does not influence margin integrity of composite restorations. Therefore, the second null hypothesis could not be rejected. 
Within the limitations of the present in vitro study, it can be concluded that demineralized enamel reduces margin integrity of composite restorations bonded with a selfetch adhesive. In contrast to the self-etch approach, the tested etch-and-rinse adhesives were able to establish similar degrees of margin integrity whether restoration margins were located in demineralized or sound enamel.

\section{Compliance with ethical standards}

Conflict of interest The authors declare that they have no conflict of interest. 


\section{References}

1. Tauböck TT, Buchalla W, Hiltebrand U, Roos M, Krejci I, Attin T. Influence of the interaction of light- and self-polymerization on subsurface hardening of a dual-cured core build-up resin composite. Acta Odontol Scand. 2011; 69:41-47.

2. Tauböck TT, Marovic D, Zeljezic D, Steingruber AD, Attin T, Tarle Z. Genotoxic potential of dental bulk-fill resin composites. Dent Mater. 2017; 33:788-795.

3. Tauböck TT, Bortolotto T, Buchalla W, Attin T, Krejci I. Influence of light-curing protocols on polymerization shrinkage and shrinkage force of a dual-cured core build-up resin composite. Eur J Oral Sci. 2010; 118:423-429.

4. Banerjee A, Pickard HM, Watson TF. Pickard's manual of operative dentistry. 9th ed. Oxford, UK: Oxford University Press; 2011.

5. De Almeida Neves A, Coutinho E, Cardoso MV, Lambrechts P, Van Meerbeek B. Current concepts and techniques for caries excavation and adhesion to residual dentin. $\mathrm{J}$ Adhes Dent. 2011; 13:7-22.

6. Kielbassa AM, Ulrich I, Schmidl R, Schüller C, Frank W, Werth VD. Resin infiltration of deproteinised natural occlusal subsurface lesions improves initial quality of fissure sealing. Int J Oral Sci. 2017; 9:117-124.

7. Tauböck TT, Zehnder M, Schweizer T, Stark WJ, Attin T, Mohn D. Functionalizing a dentin bonding resin to become bioactive. Dent Mater. 2014; 30:868-875.

8. Körner P, El Gedaily M, Attin R, Wiedemeier DB, Attin T, Tauböck TT. Margin integrity of conservative composite restorations after resin infiltration of demineralized enamel. J Adhes Dent. 2017; 19:483-489.

9. Peumans M, De Munck J, Van Landuyt KL, Poitevin A, Lambrechts P, Van Meerbeek B. A 13-year clinical evaluation of two three-step etch-and-rinse adhesives in noncarious class-V lesions. Clin Oral Investig. 2012; 16:129-137. 
10. Gamarra VSS, Borges GA, Júnior LHB, Spohr AM. Marginal adaptation and microleakage of a bulk-fill composite resin photopolymerized with different techniques. Odontology. 2018; 106:56-63.

11. Sarr M, Kane AW, Vreven J, Mine A, Van Landuyt KL, Peumans M, Lambrechts P, Van Meerbeek B, De Munck J. Microtensile bond strength and interfacial characterization of 11 contemporary adhesives bonded to bur-cut dentin. Oper Dent. $2010 ; 35: 94-104$.

12. Blunck U, Zaslansky P. Enamel margin integrity of Class I one-bottle all-in-one adhesives-based restorations. J Adhes Dent. 2011; 13:23-29.

13. Bortolotto T, Doudou W, Kunzelmann KH, Krejci I. The competition between enamel and dentin adhesion within a cavity: an in vitro evaluation of class $\mathrm{V}$ restorations. Clin Oral Investig. 2012; 16:1125-1135.

14. Peumans M, Kanumilli P, De Munck J, Van Landuyt K, Lambrechts P, Van Meerbeek B. Clinical effectiveness of contemporary adhesives: a systematic review of current clinical trials. Dent Mater. 2005; 21:864-881.

15. Buskes JA, Christoffersen J, Arends J. Lesion formation and lesion remineralization in enamel under constant composition conditions. A new technique with applications. Caries Res. 1985; 19:490-496.

16. Magalhães AC, Moron BM, Comar LP, Wiegand A, Buchalla W, Buzalaf MA. Comparison of cross-sectional hardness and transverse microradiography of artificial carious enamel lesions induced by different demineralising solutions and gels. Caries Res. 2009; 43:474-483.

17. Wiegand A, Stawarczyk B, Buchalla W, Tauböck TT, Özcan M, Attin T. Repair of silorane composite-using the same substrate or a methacrylate-based composite. Dent Mater. 2012; 28:e19-25. 
18. Ferrari R, Attin T, Wegehaupt FJ, Stawarczyk B, Tauböck TT. The effects of internal tooth bleaching regimens on composite-to-composite bond strength. J Am Dent Assoc. $2012 ; 143: 1324-1331$.

19. Bortolotto T, Betancourt F, Krejci I. Marginal integrity of resin composite restorations restored with PPD initiatorcontaining resin composite cured by QTH, monowave and polywave LED units. Dent Mater J. 2016; 35:869-875.

20. Groddeck S, Attin T, Tauböck T. Effect of cavity contamination by blood and hemostatic agents on marginal adaptation of composite restorations. J Adhes Dent. $2017 ; 19: 259-264$.

21. Frankenberger R, Hehn J, Hajtó J, Krämer N, Naumann M, Koch A, Roggendorf MJ. Effect of proximal box elevation with resin composite on marginal quality of ceramic inlays in vitro. Clin Oral Investig. 2013; 17:177-183.

22. Maresca C, Pimenta LA, Heymann HO, Ziemiecki TL, Ritter AV. Effect of finishing instrumentation on the marginal integrity of resin-based composite restorations. J Esthet Restor Dent. 2010; 22:104-112.

23. Ten Cate JM, Rempt HE. Comparison of the in vivo effect of a 0 and 1,500 ppmF MFP toothpaste on fluoride uptake, acid resistance and lesion remineralization. Caries Res. 1986; 20:193-201.

24. Paris S, Hopfenmüller W, Meyer-Lueckel H. Resin infiltration of caries lesions: an efficacy randomized trial. J Dent Res. 2010; 89:823-826.

25. Meyer-Lueckel H, Mueller J, Paris S, Hummel M, Kielbassa AM. The penetration of various adhesives into early enamel lesions in vitro. Schweiz Monatsschr Zahnmed. $2005 ; 115: 316-323$.

26. Mueller J, Meyer-Lueckel H, Paris S, Hopfenmuller W, Kielbassa AM. Inhibition of lesion progression by the penetration of resins in vitro: influence of the application procedure. Oper Dent. 2006; 31:338-345. 
27. Paris S, Meyer-Lueckel H, Mueller J, Hummel M, Kielbassa AM. Progression of sealed initial bovine enamel lesions under demineralizing conditions in vitro. Caries Res. 2006; 40:124-129.

28. Schmidlin PR, Sener B, Attin T, Wiegand A. Protection of sound enamel and artificial enamel lesions against demineralisation: caries infiltrant versus adhesive. J Dent. 2012; $40: 851-856$.

29. Barcellos DC, Batista GR, Silva MA, Pleffken PR, Rangel PM, Fernandes VV, Di Nicoló R, Torres CR. Two-year clinical performance of self-etching adhesive systems in composite restorations of anterior teeth. Oper Dent. 2013; 38:258-266.

30. Ermis RB, Van Landuyt KL, Cardoso MV, De Munck J, Van Meerbeek B, Peumans M. Clinical effectiveness of a one-step self-etch adhesive in non-carious cervical lesions at 2 years. Clin Oral Investig. 2012; 16:889-897.

31. Frankenberger R, Tay FR. Self-etch vs etch-and-rinse adhesives: effect of thermomechanical fatigue loading on marginal quality of bonded resin composite restorations. Dent Mater. 2005; 21:397-412.

32. Swanson TK, Feigal RJ, Tantbirojn D, Hodges JS. Effect of adhesive systems and bevel on enamel margin integrity in primary and permanent teeth. Pediatr Dent. 2008; 30:134140.

33. St-Pierre L, Chen L, Qian F, Vargas M. Effect of adhesive filler content on marginal adaptation of class II composite resin restorations. J Oper Esthet Dent. 2017; 2:1-7.

34. Ramesh Kumar KR, Shanta Sundari KK, Venkatesan A, Chandrasekar S. Depth of resin penetration into enamel with 3 types of enamel conditioning methods: a confocal microscopic study. Am J Orthod Dentofacial Orthop. 2011; 140:479-485.

35. Meyer-Lueckel H, Paris S, Kielbassa AM. Surface layer erosion of natural caries lesions with phosphoric and hydrochloric acid gels in preparation for resin infiltration. Caries Res. 2007; 41:223-230. 
36. Grégoire G, Ahmed Y. Evaluation of the enamel etching capacity of six contemporary self-etching adhesives. J Dent. 2007; 35:388-397.

37. De Munck J, Vargas M, Iracki J, Van Landuyt K, Poitevin A, Lambrechts P, Van Meerbeek B. One-day bonding effectiveness of new self-etch adhesives to bur-cut enamel and dentin. Oper Dent. 2005; 30:39-49.

38. Souza-Junior EJ, Prieto LT, Araújo CT, Paulillo LA. Selective enamel etching: effect on marginal adaptation of self-etch LED-cured bond systems in aged Class I composite restorations. Oper Dent. 2012; 37:195-204.

39. Taschner M, Nato F, Mazzoni A, Frankenberger R, Krämer N, Di Lenarda R, Petschelt A, Breschi L. Role of preliminary etching for one-step self-etch adhesives. Eur J Oral Sci. $2010 ; 118: 517-524$.

40. De Munck J, Van Landuyt K, Peumans M, Poitevin A, Lambrechts P, Braem M, Van Meerbeek B. A critical review of the durability of adhesion to tooth tissue: methods and results. J Dent Res. 2005; 84:118-132.

41. Loguercio AD, Luque-Martinez I, Muñoz MA, Szesz AL, Cuadros-Sánchez J, Reis A. A comprehensive laboratory screening of three-step etch-and-rinse adhesives. Oper Dent. 2014; 39:652-662.

42. Schirrmeister JF, Huber K, Hellwig E, Hahn P. Two-year evaluation of a new nanoceramic restorative material. Clin Oral Investig. 2006; 10:181-186.

43. Schmidlin PR, Huber T, Göhring TN, Attin T, Bindl A. Effects of total and selective bonding on marginal adaptation and microleakage of Class I resin composite restorations in vitro. Oper Dent. 2008; 33:629-635. 
Table 1 Composition of the adhesive systems used in the present study according to manufacturers` information

\begin{tabular}{|l|l|l|}
\hline Adhesive system (manufacturer) & Composition & LOT number \\
\hline \hline $\begin{array}{l}\text { Syntac Classic } \\
\text { (Ivoclar Vivadent, Schaan, Liechtenstein) }\end{array}$ & $\begin{array}{l}\text { Primer: Dimethacrylates, maleic acid, solvent, stabilizer } \\
\text { Adhesive: Dimethacrylates, maleic acid, glutaraldehyde, water } \\
\text { Heliobond: Bis-GMA, TEGDMA, stabilizers and catalysts }\end{array}$ & $\begin{array}{l}\text { U43425 } \\
\text { V01074 }\end{array}$ \\
\hline $\begin{array}{l}\text { Optibond FL } \\
\text { Kerr, Orange, CA, USA) }\end{array}$ & $\begin{array}{l}\text { Primer: HEMA, GPDM, ethanol, water, CQ, BHT, PAMA } \\
\text { Adhesive: Bis-GMA, HEMA, GDM, CQ, ODMAB, } \\
\text { barium aluminumborosilicate, Na2SiF, fumed silicon dioxide, } \\
\text { gamma-methacryloxypropyltrimethoxysilane }\end{array}$ & $\begin{array}{l}5554307 \\
5543327\end{array}$ \\
\hline $\begin{array}{l}\text { iBond Self Etch } \\
\text { (Heraeus, Hanau, Germany) }\end{array}$ & $\begin{array}{l}\text { UDMA, 4-META, glutaraldehyde, acetone, water, } \\
\text { photo-initiators, stabilizers }\end{array}$ & 010901 \\
\hline
\end{tabular}

4-META: 4-methacryloyloxethyl trimellitate anhydride; BHT: Butylhydroxytoluen; Bis-GMA: Bisphenol-A-glycidyldimethacrylate; CQ: Camphorquinone; GDM: Glycerol dimethacrylate; GPDM: Glycerol phosphate dimethacrylate; HEMA: 2-hydroxylethyl methacrylate; ODMAB: 2-(Ethylhexyl)-4-(dimethylamino)benzoate; PAMA: Phthailic acid monomethacrylate; TEGDMA: Triethylene glycol dimethacrylate; UDMA: Urethane dimethacrylate 


\begin{tabular}{|c|c|c|c|c|c|}
\hline \multicolumn{3}{|c|}{ Demineralization $(n=30)$ in acid buffer } & \multirow{2}{*}{\multicolumn{3}{|c|}{$\downarrow$}} \\
\hline & $\downarrow$ & & & & \\
\hline \multicolumn{3}{|c|}{ Preparation of standardized Class V cavities } & \multicolumn{3}{|c|}{ Preparation of standardized Class V cavities } \\
\hline$\downarrow$ & $\downarrow$ & $\downarrow$ & $\downarrow$ & $\downarrow$ & $\downarrow$ \\
\hline \multicolumn{6}{|c|}{$\begin{array}{l}\text { Random assignment into } 6 \text { groups }(\mathrm{n}=10 \text { per group) } \\
\text { Bonding procedure according to manufacturers' instructions for use }\end{array}$} \\
\hline Group 1 & Group 2 & Group 3 & Group 4 & Group 5 & Group 6 \\
\hline $\begin{array}{l}\text { Unfilled etch-and-rinse } \\
\text { adhesive }\end{array}$ & $\begin{array}{l}\text { Filled etch-and-rinse } \\
\text { adhesive }\end{array}$ & $\begin{array}{l}\text { Self-etch } \\
\text { adhesive }\end{array}$ & $\begin{array}{l}\text { Unfilled etch-and-rinse } \\
\text { adhesive }\end{array}$ & $\begin{array}{l}\text { Filled etch-and-rinse } \\
\text { adhesive }\end{array}$ & $\begin{array}{l}\text { Self-etch } \\
\text { adhesive }\end{array}$ \\
\hline Syntac Classic & Optibond FL & iBond Self Etch & Syntac Classic & Optibond FL & iBond Self Etch \\
\hline $\begin{array}{l}\text { Etching enamel and dentin } \\
\text { Phosphoric acid }(15 \mathrm{~s})\end{array}$ & $\begin{array}{l}\text { Etching enamel and dentin } \\
\text { Phosphoric acid (15 s) }\end{array}$ & iBond Self Etch (20 s) & $\begin{array}{l}\text { Etching enamel and dentin } \\
\text { Phosphoric acid }(15 \mathrm{~s})\end{array}$ & $\begin{array}{l}\text { Etching enamel and dentin } \\
\text { Phosphoric acid }(15 \mathrm{~s})\end{array}$ & iBond Self Etch (20 s) \\
\hline Syntac Primer (15 s) & Optibond FL Prime (15 s) & & Syntac Primer (15 s) & Optibond FL Prime $(15 \mathrm{~s})$ & \\
\hline Syntac Adhesive (10 s) & Optibond FL Adhesive (15 s) & & Syntac Adhesive (10 s) & Optibond FL Adhesive (15 s) & \\
\hline Heliobond (15 s) & Light curing (20 s) & & Heliobond (15 s) & Light curing $(20 \mathrm{~s})$ & \\
\hline Light curing $(20 \mathrm{~s})$ & & & Light curing $(20 \mathrm{~s})$ & & \\
\hline$\downarrow$ & $\downarrow$ & $\downarrow$ & $\downarrow$ & $\downarrow$ & $\downarrow$ \\
\hline \multicolumn{6}{|c|}{ Application of a nanofilled composite (Filtek Supreme XTE), light curing (20 s) } \\
\hline \multicolumn{6}{|c|}{$\downarrow$} \\
\hline \multicolumn{6}{|c|}{ Thermocycling $5000 \mathrm{x}\left(5-55^{\circ} \mathrm{C}\right)$} \\
\hline \multicolumn{6}{|c|}{$\downarrow$} \\
\hline \multicolumn{6}{|c|}{ Replica production and quantitative margin analysis (scanning electron microscopy) } \\
\hline \multicolumn{6}{|c|}{1} \\
\hline & & & alysis & & \\
\hline
\end{tabular}

Fig. 1 Experimental design 


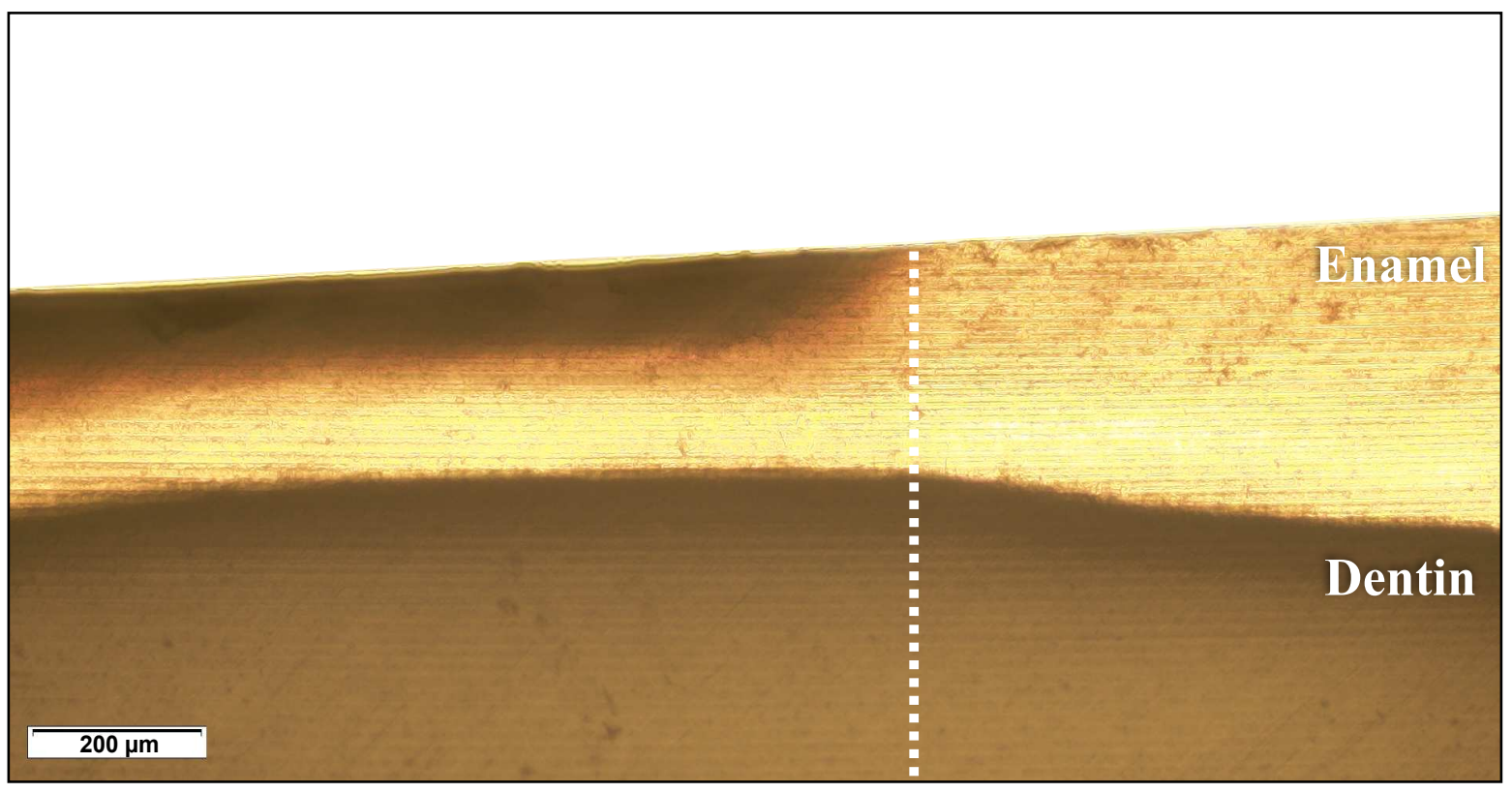

Fig. 2 Cross-sectional cut of an artificially demineralized enamel lesion after 21 days in acid buffer (left side) vs. no demineralization (right side) 


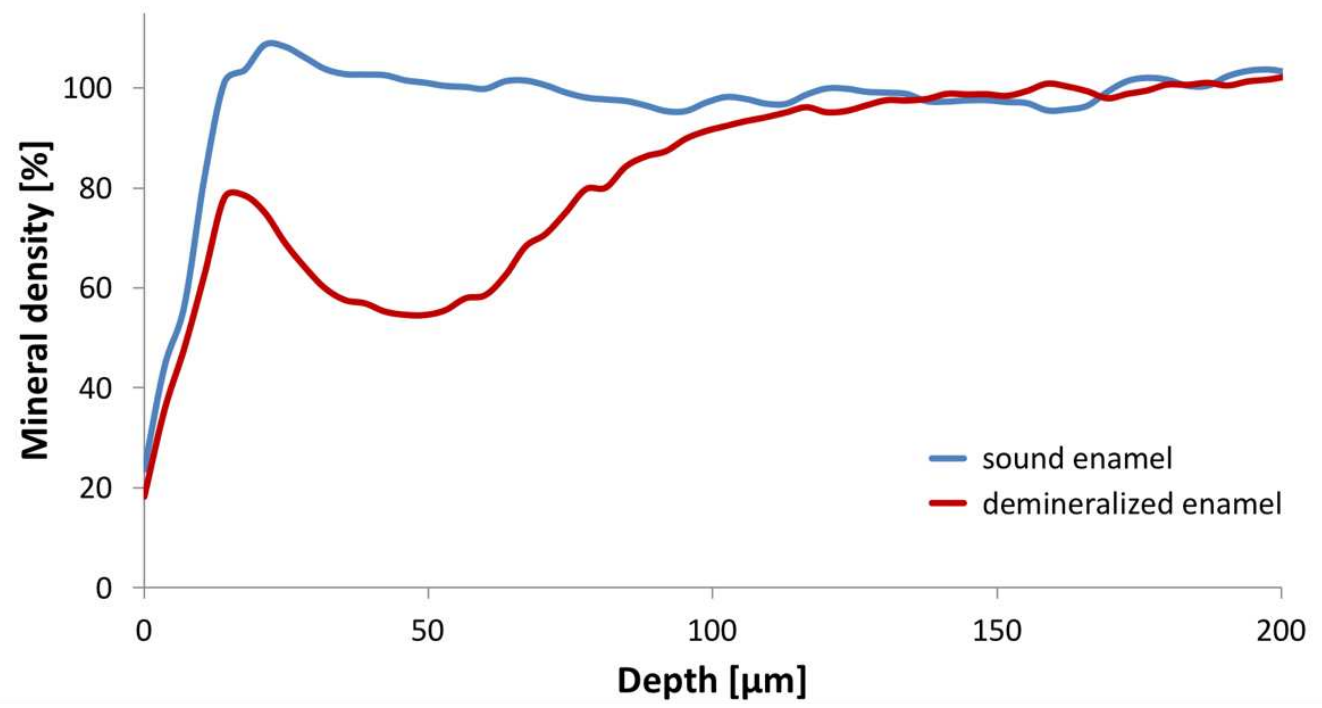

Fig. 3 Percentages of mineral density of sound and demineralized enamel related to the (lesion) depth in $\mu \mathrm{m}$ measured by transverse microradiography (TMR) 


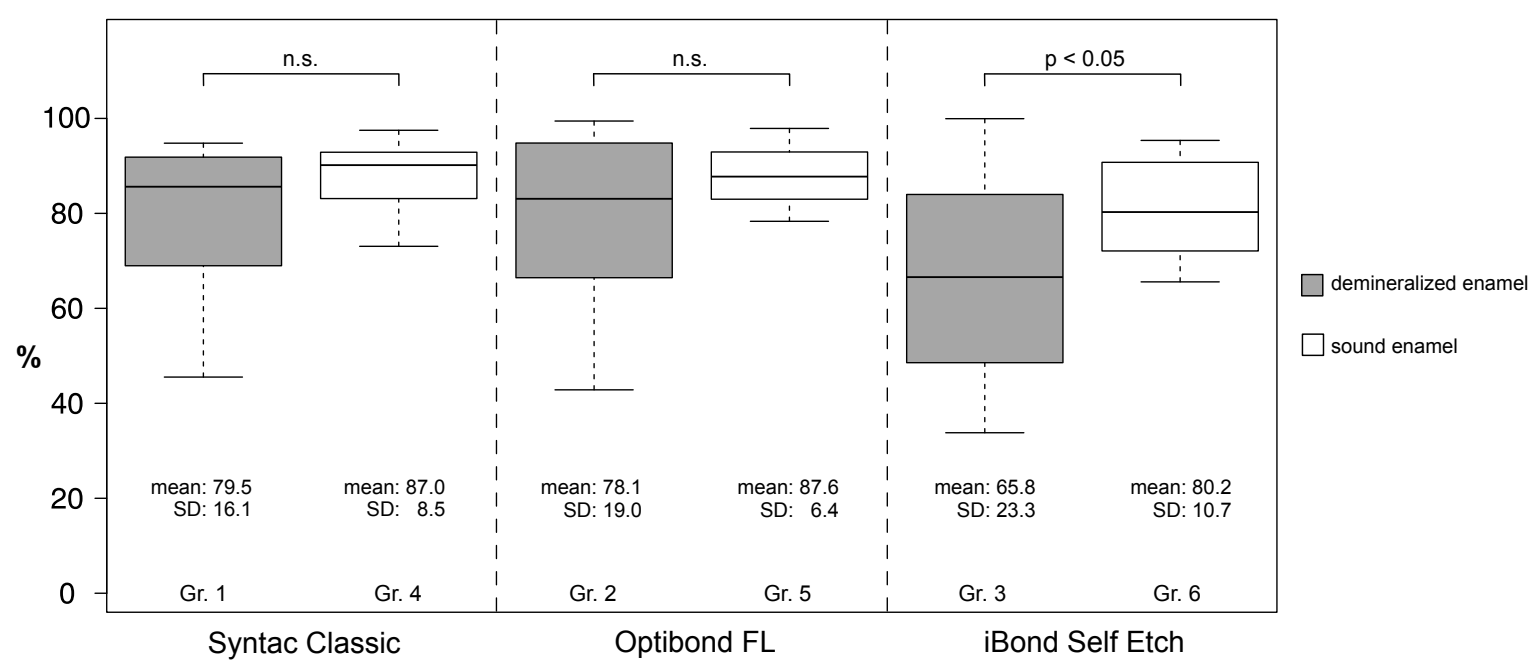

Fig. 4 Percentages of continuous enamel margins of composite restorations in demineralized and sound enamel, respectively, using Syntac Classic, Optibond FL, and iBond Self Etch as adhesives. The boxplots show the medians (black lines) with 25 and $75 \%$ quartiles (boxes); the whiskers represent $1.5 *$ IQR (interquartile range) or minima and maxima of the distribution if below $1.5 * \mathrm{IQR}$ 


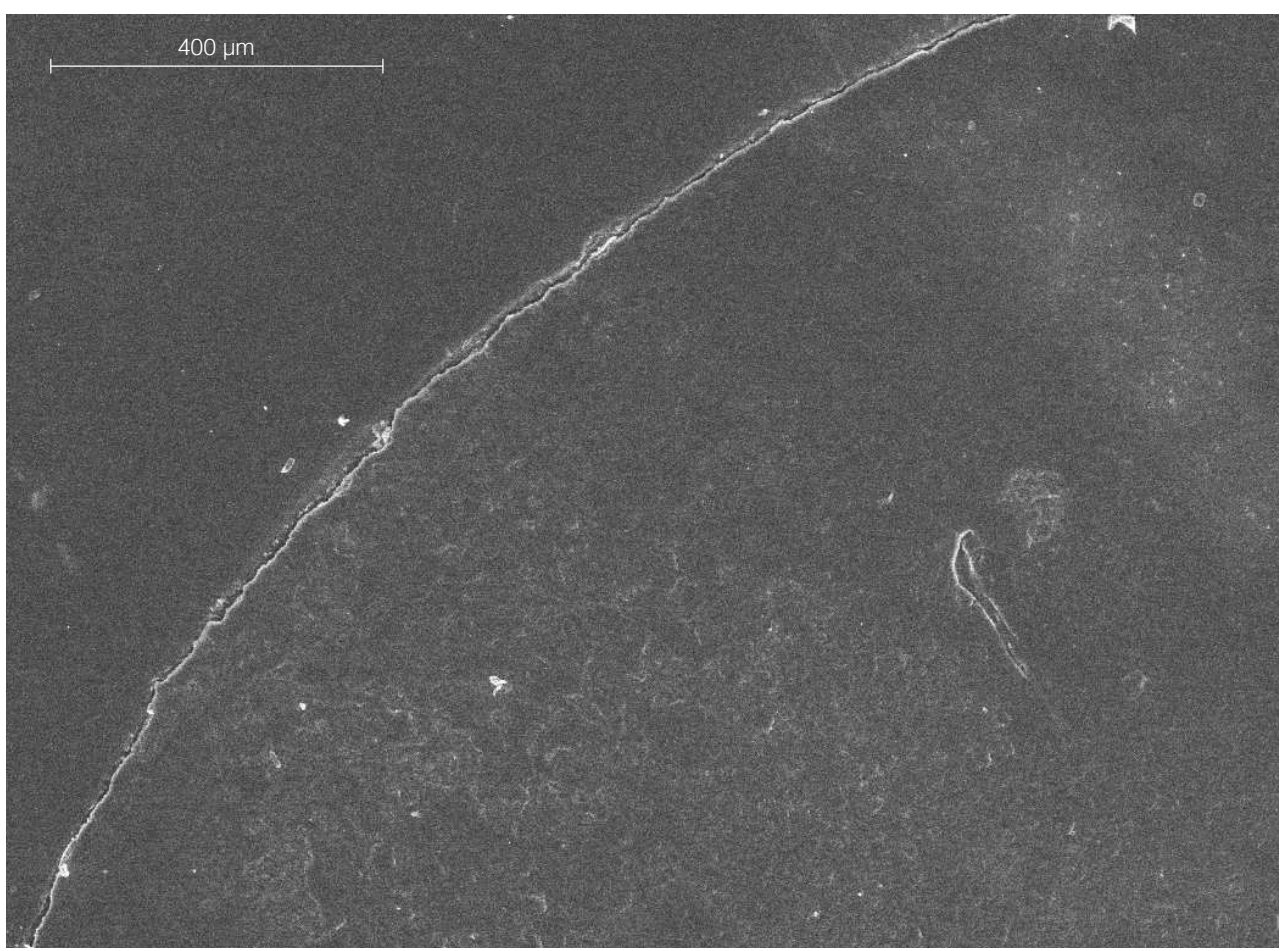

Fig. 5 SEM micrograph of non-continuous margin (group 3; iBond Self Etch in demineralized enamel)

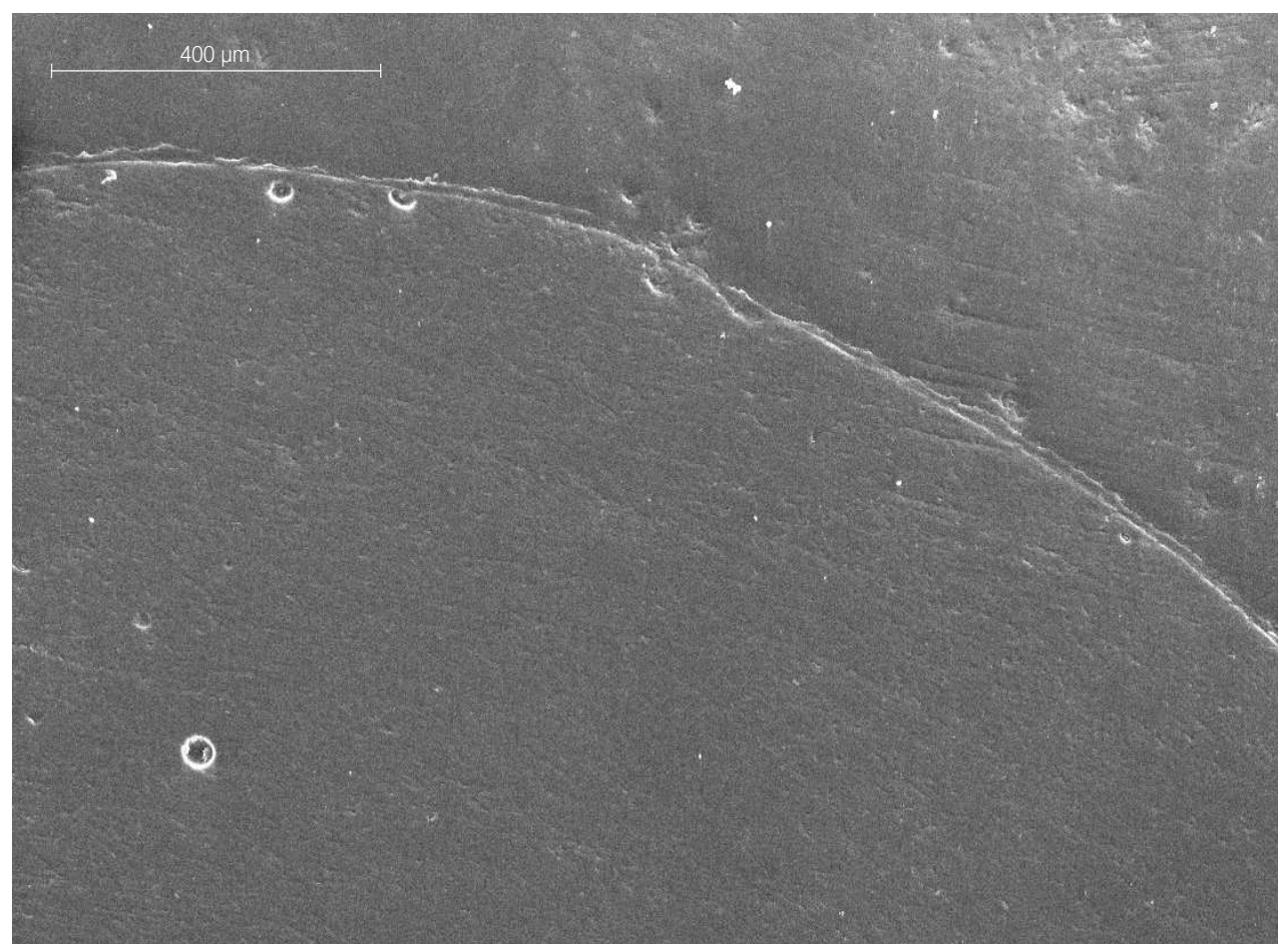

Fig. 6 SEM micrograph of continuous margin (group 6; iBond Self Etch in sound enamel) 